\title{
Evaluation of Antifungal Activity of Plant Extracts against Papaya Anthracnose (Colletotrichum gloeosporioides)
}

\author{
Anteneh Ademe $^{1 *}$, Amare Ayalew ${ }^{2}$ and Kebede Woldetsadik ${ }^{2}$
}

${ }^{1}$ Sekota Dryland Agricultural Research Center, Sekota, Ethiopia

${ }^{2}$ Department of Plant Sciences, Haramaya University, Haramaya, Ethiopia

\begin{abstract}
Antifungal activities of nineteen plant extracts were tested in 2010 with the objectives of screening potential plant extracts against Colletotrichum gloeosporioides under in vitro and anthracnose caused by Colletotrichum gloeosporioides, on papaya (Carica papaya L.) during storage. Ethyl acetate extracts of Lantana camara resulted in the highest inhibition (with inhibition zone of $35.3 \mathrm{~mm}$ ) and showed strong activity against $C$. gloeosporioides. Inhibition levels of spore germination that reached $88.7,85.8,85.1$ and $84.6 \%$ were recorded over the control by extracts of Lantana camara, Lantana viburnoides, Echinops sp. and Ruta chalepensis. Four aqueous extracts were evaluated for control of anthracnose under in vivo for 14 days, and Echinops sp. (25\%) was found to be most effective in the reduction of disease development and maintaining the overall quality of papaya fruit. Further studies on isolation and characterization of the active (antifungal) compounds are needed.
\end{abstract}

Keywords: Anthracnose; Colletotrichum gloeosporioides; Ethyl acetate; Papaya

\section{Introduction}

Papaya (Carica papaya L.) is a popular and economically important fruit tree of tropical and subtropical countries [1]. The leading global producers of papaya are Brazil, Colombia, Democratic Republic of Congo, Ethiopia, Guatemala, India, Indonesia, Mexico, Nigeria and Philippines [2]. Papaya is known as "common man's fruits". It is rich sources of vitamin A, C and calcium. The ripe fruit is prone to many diseases, among which anthracnose caused by Colletotrichum gloeosporioides (Penz.) Penz \& Sacc. is an economically important disease during transit, storage and market [3-5]. In general, the fungus initiates infection as soon as flowering starts and stays latent until the postharvest environment conditions favor colonization of fruit tissue $[3,6]$. According to Coursey [7], postharvest losses of approximately 40$100 \%$ have been generally reported in papaya in developing countries.

Synthetic fungicides are currently used as the primary means for the control of plant diseases. However, the alternative control methods are needed because of the negative public perceptions about the use of synthetic chemicals, resistance to fungicides among fungal pathogens and high development cost of new chemicals $[8,9]$. Application of higher concentrations of chemicals in an attempt to overcome anthracnose disease increases the risk of high levels of toxic residues, which is, particularly serious, since papaya fruit is consumed in relatively short time after harvest [10].

Bioactive products of plants are less persistent in environment and are safe for mammals, other non target organisms [11-13], and for the control of postharvest disease than synthetics [14]. A number of plant species have been reported to possess natural substances that are toxic to many fungi causing plant diseases $[15,16]$. Ranaware et al. [17] indicated the efficacy of aqueous plant extracts as potential inhibitors of Alternaria carthami. Similarly, Dwivedi and Shukla [18] reported the effectiveness of aqueous extracts of different species of plants against Fusarium oxysporum.

Papaya anthracnose is one of the major diseases of the crop in Ethiopia [19]. Hence, this study was conducted with objective of determining the in vitro effect of plant extracts on conidial germination, mycelial growth of Colletotrichum gloeosporioides and their efficacy against the development of postharvest papaya anthracnose.

\section{Materials and Methods}

\section{Isolation of target pathogen}

Colletotrichum gloeosporioides was isolated from papaya fruits showing anthracnose lesions. An isolate of the pathogen grown in pure culture was maintained in PDA culture tubes at $4^{\circ} \mathrm{C}$, and used as stock culture throughout the study $[20,21]$.

\section{In vitro evaluation of botanicals}

Sample collection and extraction: The potential extracts were selected from a screening of nineteen plant species. The plants were collected from Haramaya and Ambo areas of Ethiopia, in 2010. The experiment was conducted at the Plant Pathology Laboratory of the School of Plant Sciences at Haramaya University. The plant specimens (leaves) were shade dried at a room temperature and milled into a fine powder. Following the procedures employed by Amare [22], 50 gram of the pulverized plant specimens were extracted with $250 \mathrm{ml}$ ethyl acetate by stirring for 2 hrs on magnetic stirrer. The extract was filtered through folded filter paper into a $500 \mathrm{ml}$ round bottom flask and reduced to dryness on a rotary evaporator at $40^{\circ} \mathrm{C}$ water bath temperature. About $50 \mathrm{mg}$ of the ethyl acetate extracts of each plant was weighed, redissolved in $1 \mathrm{ml}$ of the extraction solvent and then tested for antifungal activities.

*Corresponding author: Anteneh Ademe, Sekota Dryland Agricultural Research Center, P.O. Box 62, Sekota, Ethiopia, Tel: +25133 4401100; Fax: +25133 4400409; E-mail: ad.antish@gmail.com

Received: September 25, 2013; Accepted November 09, 2013; Published November 14, 2013

Citation: Ademe A, Ayalew A, Woldetsadik K (2013) Evaluation of Antifungal Activity of Plant Extracts against Papaya Anthracnose (Colletotrichum gloeosporioides). J Plant Pathol Microb 4: 207. doi:10.4172/2157-7471.1000207

Copyright: ( 2013 Ademe A, et al. This is an open-access article distributed under the terms of the Creative Commons Attribution License, which permits unrestricted use, distribution, and reproduction in any medium, provided the original author and source are credited. 
Paper disc assay: Filter paper discs, $6 \mathrm{~mm}$ diameter, were sterilized by dry heat for $1 \mathrm{~h}$ at $160^{\circ} \mathrm{C}$ oven temperature and impregnated with each of the test extracts by applying $10 \mu \mathrm{L}$ of the extract solution using a capillary pipette. The culture media containing spore suspension of Colletotrichum gloeosporioides was poured into $14.5 \mathrm{~cm}$ in diameter petri plate and allowed to solidify. After the carrier solvent evaporated from the paper discs, they were placed on the surface of the medium; the plates were incubated for 4 days. The diameter of inhibition zone was measured in $\mathrm{mm}$ and the degree of inhibition of the fungal growth expressed on a $0-4$ scale was recorded, where $0=$ no inhibition zone visible, $1=$ inhibition zone barely distinct, fungal growth and sporulation only slightly inhibited, $2=$ inhibition zone well distinct, fungal growth ca. $50 \%$ of the control, slight sporulation, $3=$ inhibition zone with sparse (ca. 25\% of the control) fungal growth, and $4=$ inhibition zone free of visible fungal growth [22] (Figure 1a and 1b).

Conidial germination test: Conidia of C. gloeosporioides were adjusted using hemacytometer to a concentration of $10^{5}$ condia $/ \mathrm{ml}$. Ten $\mu \mathrm{L}$ of plant extracts and $90 \mu \mathrm{L}$ of the conidial suspension were mixed and the mixtures were added to the surface of dried depression slides. The slides were then placed on a glass rod in petri dish under moistened conditions and incubated at $25^{\circ} \mathrm{C}$ for $24 \mathrm{~h}$. Control conidia received an equivalent amount of the solvent. After incubation, slides were fixed in lactophenol cotton blue and observed microscopically for spore germination. The experiment was laid out in CRD with three replications. The number of conidia germinated was scored to calculate the percentage inhibition of conidial germination.

\section{In vivo antifungal assay of plant extracts}

Aqueous extracts were tested for their effect on the papaya anthracnose development on harvested fruit. "Solo" papaya was obtained from Yilma State Farm in Dire Dawa, Ethiopia. For this purpose, undamaged, matured fruits of comparable size, color class and free from any pesticide were used. Aqueous solutions of selected plant species were evaluated at a concentration of 10 and $25 \%$. Conidial suspension of C. gloeosporioides was prepared and adjusted to $10^{5}$ conidia/ml Papaya fruits were surface-sterilized by dipping in $1 \%$ sodium hypochlorite solution for $10 \mathrm{~min}$, rinsed in sterile distilled water and inoculated by dipping into spore suspension of C. gloeosporioides. After incubation for $15 \mathrm{~h}$ in plastic bag, fruits were dipped into extracts, while the control fruits were dipped into sterile distilled water. Five fruits (i.e. replications) for each concentration of extracts were used and arranged in CRD [21]. As of first symptom appearance, data on incidence and severity of anthracnose was recorded. Disease incidence was expressed as the percentage of fruits showing symptom. Disease severity was rated on 1 to 5 scale, where $1=0 \%$ of surface fruit rotten, $2=1-25 \%, 3=26-50 \%, 4=51-75 \%$, and $5=76-100 \%$ [23]. Overall quality was assessed according to the following score: 1-2= fruit not marketable; $3=$ poor quality, limited marketability; 4-5=fair quality, marketable; 6-7=good quality, marketable; 8-9=excellent quality [24]. Percentage of marketability was assessed as a ratio of the number of fruits with scores 6, 7 for overall quality against the total number of fruits [25].

\section{Statistical analysis}

Analysis of variance (ANOVA) was carried out with the statistical software SAS v. 9.0 and Least Significant Difference (LSD) at 5\% probability level were used for mean comparison. Severity was square root transformed, while spore germination was arcsine transformed before statistical analysis.

\section{Results and Discussion}

\section{In vitro effect of botanicals on mycelial growth and spore germination of Colletotrichum gloeosporioides}

There was a highly significant difference $(\mathrm{P}<0.0001)$ among the antifungal effects of ethyl acetate extracts on inhibition zone and degrees of inhibition against the test fungus. Extracts of Echinops sp. and Lantana camara more strongly inhibited growth of the pathogen than the remaining extracts. On the other hand, the inhibition resulting from other extracts of both solvents ranged from weak to moderately active. Ethyl acetate extracts of Lantana camara had the highest inhibition zone among plants. This was followed by Artemisia afara, Echinops sp., Lantana viburnoides, Ruta chalepensis and Vernonia amygdalina (Table 1). Lantana camara were found to be superior in mycelial growth reduction among different botanical tested against anthracnose of papaya [5]. The preservative nature of some plant extracts has been known for centuries, and there has been renewed interest in the antimicrobial properties of extracts from aromatic plants $[12,26]$. Numerous investigations on the genus Echinops have resulted in the isolation of thiophenes. Thiophenes from Echinops have been reported to possess many biological activities, including insecticidal and fungicidal [13]. Bautista-Banos et al. [23] tested leaf and stem
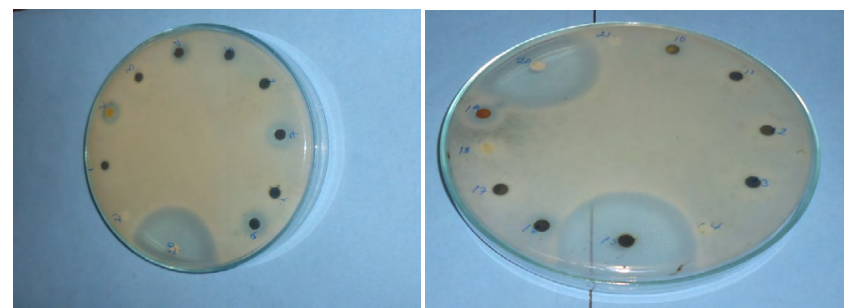

Figure 1: a and 1b: In vitro inhibition effect of botanicals on Colletotrichum gloeosporioides on PDA (Paper disc labeled as 2, 4, 5, 6, 7, 9, 10, 12, 13 15, 16, 19, 20 and 21 was Echinops sp., Artemisia afara, Ruta chalepensis, Thymus serrulatus, Lantana viburnoides, Vernonia amygdalina, Ocimum sp. Citrus limon, Nicotinia tabacum, Lantana camara, Ocimum lamifolium, Zingiber officinale, carbendazim and ethyl acetate, respectively).

\begin{tabular}{|c|c|c|c|c|}
\hline Species & Family & $\mathbf{D I}(\mathbf{m m})^{\mathbf{a}}$ & $\mathbf{I E}^{\mathbf{b}}$ & Spore germination (\%) \\
\hline Artemisia afara & Asteraceae & 4.5 & 3 & 18.8 \\
\hline Citrus limon & Rutaceae & 1.3 & 1 & 46.1 \\
\hline Echinops sp. & Asteraceae & 5.7 & 4 & 13.3 \\
\hline Lantana camara & Verbenaceae & 35.3 & 4 & 10.1 \\
\hline Lantana viburnoides & Verbenaceae & 5.0 & 3 & 12.6 \\
\hline Nicotinia tabacum & Solanaceae & 1.0 & 3 & 42.6 \\
\hline Ocimum lamifolium & Lamiaceae & 2.5 & 3 & 24.7 \\
\hline Ocimum sp. & Lamiaceae & 2.2 & 3 & 30.9 \\
\hline Ruta chalepensis & Rutaceae & 4.5 & 3 & 13.7 \\
\hline Thymus serrulatus & Lamiaceae & 1.8 & 2 & 18.1 \\
\hline Vernonia amygdalina & Asteraceae & 5.3 & 3 & 16.3 \\
\hline Zingiber officinale & Zingiberaceae & 4.0 & 3 & 16.8 \\
\hline Control & - & 0.0 & 0 & 89.1 \\
\hline LSD $(0.05)$ & & 1.41 & & 4.32 \\
\hline
\end{tabular}

adiameter of inhibition zone in $\mathrm{mm}$ measured after 4 days of incubation binhibition effect on a $0-4$ scale, where $0=$ none and $4=$ strong inhibition 'spore germination $24 \mathrm{~h}$ after treatment Values are means of three replications

Table 1: Antifungal activity of some plant species from Ethiopia against $C$. gloeosporioides. 
extracts of various plant species against Colletotrichum gloeosporioides. In in vitro experiment, leaf extracts of Citrus limon were found to be inhibitive the in vitro radial growth of C. gloeosporioides. In general, the presence of antimicrobial substances in the different extracts which caused the inhibition of radial growth in vitro agrees with reports of other studies [27-29].

The result of the in vitro screening tested against C. gloeosporioides revealed that there was a highly significant difference $(\mathrm{P}<0.0001)$ in effects among ethyl acetate extracts of plants on spore germination (Table 1). From tested extracts, Lantana camara gave the lowest spore germination (10.1\%), followed by Lantana viburnoides (12.6\%), Echinops sp. (13.3\%) and Ruta chalepensis (13.7\%), with no significant difference among them. The remaining ethyl acetate extracts showed also varying degrees of inhibition of spore germination ranging from $84.6 \%$ in Ruta chalepensis to $48.3 \%$ in Citrus limon (Table 1). Commercial essential oils of Ruta chalepensis and Thymus vulgaris and extracts of Ocimum basilicum and Vernonia amygdalina were found to be effective in reducing conidial germination of $C$. gloeosporioides [14,30]. Antifungal activities of 13 plant extracts were tested against conidial germination of C. gloeosporioides and Zingiber officinales were reported to be effective in minimizing conidial germination [31].

\section{Effect of extracts on anthracnose development and quality of papaya}

Extracts of botanicals evaluated for their efficacy against papaya anthracnose on papaya fruit that had been artificially inoculated by C. gloeosporioides showed a highly significant difference $(\mathrm{P}<0.0001)$ among the treatments in the incidence and severity of the disease. The incidence and severity of anthracnose was lowest in fruits treated with Echinops sp. extract, which were statistically at par with the positive control. Within the aqueous extract concentrations, fruits treated with $25 \%$ had relatively lower incidence and severity of anthracnose than those treated with $10 \%$ aqueous extracts, with the exception of Ruta chalepensis and Thymus serrultus. Overall, fruits treated with aqueous plant extracts had lower severity than the untreated control (Figure 2a and $2 b$ ). Water is a universal solvent, used to extract plant products with antimicrobial activity. Nearly all of the identified antimicrobial compounds from plants are aromatic or saturated organic compounds, thus water is among other solvents that are most commonly used for preliminary investigation of antimicrobial activity in plants [32]. The presences of Furoquinolines and coumarins are reported in Rutaceae family to exhibit antifungal activity [33,34]. The antimicrobial properties of extracts from various species have been proven to affect fungal development in vivo $[24,30,35]$.

In this study, there was a highly $(\mathrm{P}<0.0001)$ significant difference in marketability of fruits treated with extracts. The results showed that extracts of different plant species substantially varied in their antifungal potentials and the difference might accrue from the variability in chemical constituents of the plants. The highest marketability was achieved in fruits treated with Echinops sp. extracts at a concentration of $25 \%$ (Figure 2c). Bhaskara et al. [36] reported the antifungal activity of thyme oil against $B$. cinerea and R. stolonifer. Similarly, the inhibitory effects of thyme oil against $C$. gloeosporioides growth in in vitro evaluations and over development of storage rots in papaya fruit [37].

Postharvest diseases like C. gloeosporioides greatly reduce the storage life papayas. However, dipping fruit in plant extracts inhibited rot development during storage [35,38]. Navel orange fruits treated with aqueous extract kept on quality of navel orange under cold storage
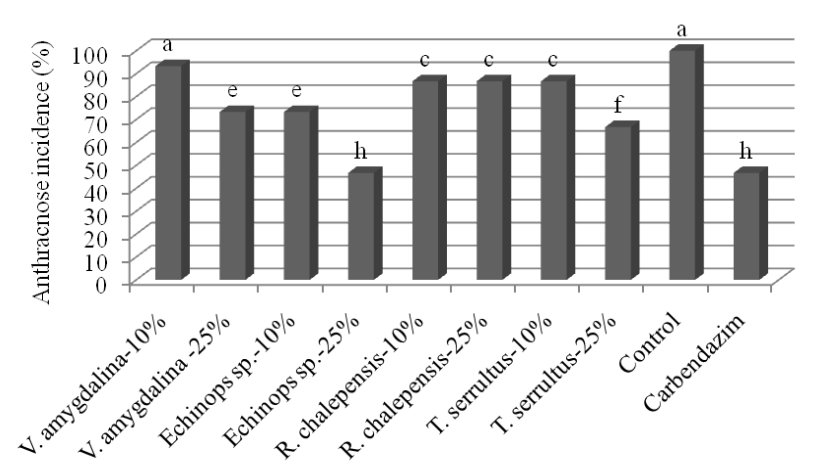

(a)

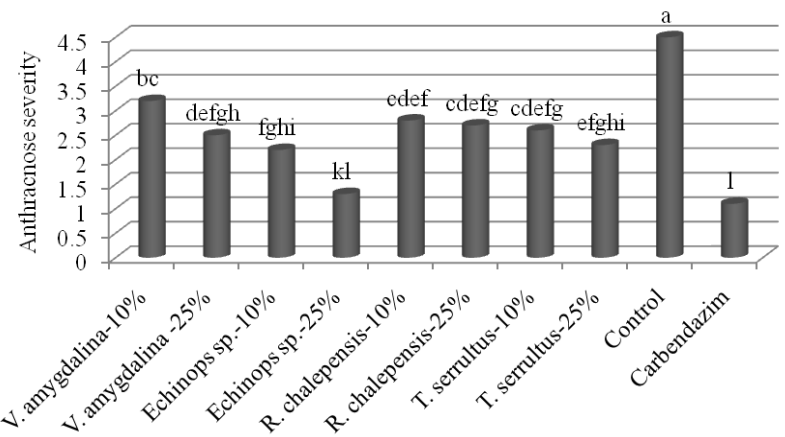

(b)

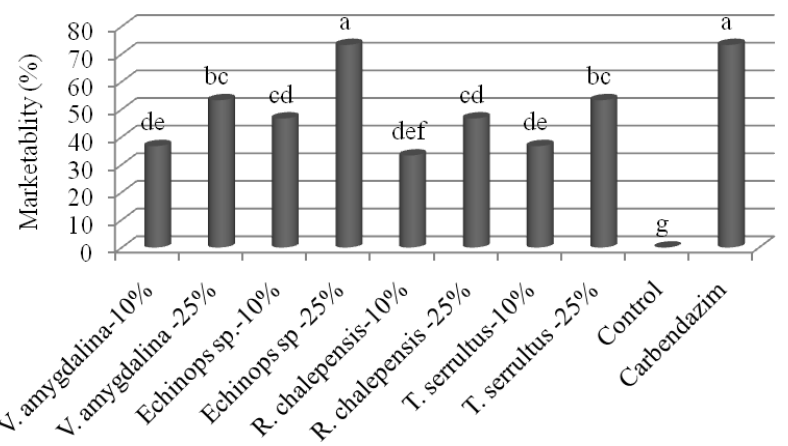

(c)

Figure 2: (a) Effect of plant extracts on anthracnose incidence of artificially inoculated papaya fruit. (b) Effect of plant extracts on anthracnose severity of artificially inoculated papaya fruit. (c) Effect of plant extracts on overall quality of artificially inoculated papaya fruit. Bars followed by common letters are not statistically different (LSD test, $P \leq 0.05$ ).

condition, and reduced the incidence and severity of green rot disease comparing with the control treatment [27]. The report by Anthony et al. [39] also showed that extracts was effective in controlling postharvest diseases, while maintaining the fruit quality. Plants are known to contain a number of secondary substances like phenols, flavonoids, quinines, essential oils, alkaloids, saponins and steroids. Some of these plant-based metabolites have antimicrobial properties, and are toxic to phytopathogens [40].

\section{Conclusions}

Examination of plant extracts on C. gloeosporioides in this study showed promising prospects for the utilization of plant extracts in 
Citation: Ademe A, Ayalew A, Woldetsadik K (2013) Evaluation of Antifungal Activity of Plant Extracts against Papaya Anthracnose (Colletotrichum gloeosporioides). J Plant Pathol Microb 4: 207. doi:10.4172/2157-7471.1000207

postharvest disease control. In vivo experiments showed that Echinops sp. $(25 \%)$ extract reduced postharvest diseases on papaya caused by $C$. gloeosporioides, while maintaining overall quality of the fruit. Further studies on isolation and characterization of the active (antifungal) compound are needed.

\section{References}

1. Teixeira da Silva JA, Rashid Z, Nhut DT, Sivakumar D, et al. (2007) Papaya (Carica papaya L.) biology and biotechnology. Tree For Sci Biotech 1: 47-73.

2. Lustria JUJ, Nacional A, Morillo AE (2009) Commodity situation report: Papaya Working Paper 34

3. Alvarez AM, Nishijima WT (1987) Postharvest diseases of papaya. Plant Dis 71: $681-686$

4. Paull RE, Nishijima W, Reyes M, Cavaletto C (1997) A review of postharvest handling and losses during marketing of papaya (Carica papaya L.). Postharvest Biol Tec 11: 165-179.

5. Tasiwal V, Benagi VI, Hegde YR, Kamanna BC, Naik KR (2009) In vitro evaluation of botanicals, bioagents and fungicides against anthracnose of papaya caused by Colletotrichum gloeosporioides (Penz.) Penz. and Sacc. Karnataka J Agric Sci 22: 803-806.

6. Capdeville G de, Souza Jr MT, Santos JRP, Miranda SP, Caetano AR, et al (2007) Scanning electron microscopy of the interaction between Cryptococcus magnus and Colletotrichum gloeosporioides on papaya fruit. Pesq Agropec Bras 42: 1537-1544.

7. Coursey DG (1983) Post-harvest losses in perishable foods of the developing world. NATO Advance Study Institute Series A46 485.

8. Lee SO, Choi GJ, Jang KS, Lim HK, Cho KY, et al. (2007) Antifungal activity of five plant essential oils as fumigant against postharvest and soilborne plant pathogenic fungi. Plant Pathol J 23: 97-102.

9. Anand T, Bhaskaran R (2009) Exploitation of plant products and bioagents for ecofriendly management of chilli fruit rot disease. J Plant Prot Res 49: 195-203.

10. Hernandez-Albiter RC, Barrera-Necha LL, Bautista-Banos S, Bravo-Luna L (2007) Antifungal potential of crude plant extracts on conidial germination of two isolates of Colletotrichum gloeosporioides (Penz.) Penz. And Sacc. Mex J Phytopathol 25: 180-185.

11. Meepagala KM, Sturtz G, Wedge DE (2002) Antifungal constituents of the essential oil fraction of Artemisia dracunculus L. var. dracunculus. J Agric Food Chem 50: 6989-6992.

12. Sharma N, Trivedi PC (2002) Screening of leaf extracts of some plants for their nematicidal and fungicidal properties against Meloidogyne incognita and Fusarium oxysporum. Asian J Exp Sci 16: 21-28.

13. Fokialakis N, Cantrell CL, Duke SO, Skaltsounis AL, Wedge DE (2006) Antifungal activity of thiophenes from Echinops ritro. J Agri Food Chem 54: 1651-1655.

14. Barrera-Necha LL, Bautista-Banos S, Flores-Moctezuma HE, Estudillo AR (2008) Efficacy of essential oils on the conidial germination, growth of Colletotrichum gloeosporioides (Penz.) Penz. and Sacc. and control of postharvest diseases in papaya (Carica papaya L.). Plant Pathol J 7: 174-178.

15. Amadioha AC (2000) Controlling rice blast in vitro and in vivo with extracts of Azadirachta indica. Crop Prot 19: 287-290.

16. Sateesh K, Marimuthu T, Thayumanavan B, Nandakumar R, Samiyappan R (2004) Antimicrobial activity and induction of systemic resistance in rice by lea extract of Datura metel against Rhizoctonia solani and Xanthomonas oryzae pv.oryzae. Physiol Mol Plant Pathol 65: 91-100.

17. Ranaware A, Singh V, Nimbkar N (2010) In vitro antifungal study of the efficacy of some plant extracts for inhibition of Alternaria carthami fungus. Indian J Nat Prod Resour 1: 384-386.

18. Dwivedi BP, Shukla DN (2000) Effect of leaf extracts of some medicinal plants on spore germination of some Fusarium species. Karnataka J Agric Sci 13 153-154.

19. Yesuf M, Mandefro W, Ahmed E, Adugna G, Tadesse D, et al. (2009) Review of Research on fruit crop diseases in Ethiopia. In: Increasing crop production through improved plant protection-Volume II, Abraham Tadesse (Ed.), Plant protection society of Ethiopia (PPSE), PPSE and EIAR, Addis Ababa, Ethiopia.
20. Gamagae SU, Sivakumar D, Wijeratnam RSW, Wijesundera RLC (2003) Use of Sodium bicarbonate and Candida oleophila to control anthracnose in papaya during storage. Crop Prot 22: 775-779.

21. Yonas K, Amare A (2008) Postharvest biological control of anthracnose (Colletotrichum gloeosporioides) on mango (Mangifera indica L). Postharvest Biol Tec 50: 8-11.

22. Amare AM (2002) Mycoflora and mycotoxins of major cereal grains and antifungal effects of selected medicinal plants from Ethiopia. Doctora Dissertation. Georg-August University of Gottingen. Cuvillier Verlag Gottingen.

23. Bautista-Banos S, Barrera-Necha LL, Bravo-Luna L, Bermudez-Torres K (2002) Antifungal activity of leaf and stem extracts from various plant species on the incidence of Colletotrichum gloeosporioides of papaya and mango fruit after storage. Mex J Phytopathol 20: 8-12.

24. Sivakumar D, Hewarathgamagae NK, Wijeratnam RSW, Wijesundera RLC (2002) Effect of ammonium carbonate and sodium bicarbonate on anthracnose of papaya. Phytoparasitica 30: 486-492.

25. Gamagae SU, Sivakumar D, Wijesundera RLC (2004) Evaluation of postharvest application of sodium bicarbonate incorporated wax formulation and Candida oleophila for the control of anthracnose of papaya. Crop Prot 23: 575579 .

26. Tripathi P, Shukla AK (2007) Emerging non-conventional technologies for control of postharvest diseases of perishables. Fresh Prod 1: 111-120.

27. Abd-El-Khair H, Omima, MH (2006) Effect of aqueous extracts of some medicinal plants in controlling the green mould disease and improvement of stored "Washington" navel orange quality. J Appl Sci Res 2: 664-674.

28. Nashwa SMA, Abo-Elyousr KAM (2012) Evaluation of various plant extracts against the early blight disease of tomato plants under greenhouse and field conditions. Plant Prot Sci 48: 74-79.

29. Al-Samarrai GF, Harbant S, Mohamed S (2013) Extacts some plants on controlling green mold of orange and on postharvest quality parameters. World Appl Sci J 22: 564-570

30. Ogbebor ON, Adekunle AT, Enobakhare DA (2007) Inhibition of Colletotrichum gloeosporioides (Penz) Penz. and Sacc. causal organism of rubber (Hevea brasiliensis Muell. Arg.) leaf spot using plant extracts. Afr J Biotechol 6: 213218.

31. Imtiaj A, Rahman SA, Alam S, Parvin R, Farhana KM, et al. (2005) Effect of fungicides and plant extracts on the conidial germination of Colletotrichum gloeosporioides causing mango anthracnose. Mycobioloby 33: 200-205.

32. Gurjar MS, Shahid A, Masood A, Kangabam SS (2012) Efficacy of plant extracts in plant disease management. Agric Sci 3: 425-433.

33. Gray Al, Watermann PG (1978) Coumarins in the Rutaceae. Phytochemistry 17: $845-864$

34. Michael JP (2003) Quinoline, quinazoline and acridone alkaloids. Nat Prod Rep 20: $476-493$

35. Bautista-Banos S, Hernandez-Lopez M, Bosquez-Molina E, Wilson CL (2003) Effects of chitosan and plant extracts on growth of Colletotrichum gloeosporioides, anthracnose levels and quality of papaya fruit. Crop Prot 22 1087-1092.

36. Bhaskara MV, Angers P, Gosselin A, Arul J (1998) Characterization and use of essential oil from Thymus vulgaris against Botrytis cinerea and Rhizopus stolonifer in strawberry fruits. Phytochemistry 47: 1515-1520.

37. Bosquez-Molina E, Ronquillo-de Jesus E, Bautista-Banos S, Verde-Calvo JR Morales-Lopez J (2010) Inhibitory effect of essential oils against Colletotrichum gloeosporioides and Rhizopus stolonifer in stored papaya fruit and their possible application in coatings. Postharvest Biol Tec 57: 132-137.

38. Bautista-Banos S, Hernandez-Lopez M, Diaz-Perez JC, Cano-Ochoa CF (2000) Evaluation of the fungicidal properties of plant extracts to reduce Rizopus stolonifer of 'ciruela' (Spondias purpurea L.) during storage. Postharvest Biol Tec 18: 67-73

39. Anthony S, Abeywickrama K, Wijeratnam SW (2003) The effect of spraying essential oils of Cymbopogon nardus, Cymbopogan flexuosus and Ocimum basilicum on postharvest diseases and storage life of Embul banana. J Hortic Sci Biotech 78: 780-785.

40. Tripathi P, Shukla AK (2010) Exploitation of botanicals in the management of phytopathogenic and storage fungi. In: Management of fungal plant pathogens, Arya A, Perello AE (Ed.), CAB International, USA 36-50. 